\title{
Women's empowerment following disaster: a longitudinal study of social change
}

\author{
Jenny Moreno' ${ }^{1}$ Duncan Shaw ${ }^{2}$
}

Received: 7 August 2017/Accepted: 31 January 2018/Published online: 12 February 2018

(C) The Author(s) 2018. This article is an open access publication

\begin{abstract}
This paper examines changes in gender relations in a small coastal community as a result of the 2010 Chile earthquake and tsunami. Vulnerability and resilience are used as a conceptual framework to analyse these changes. Based on empirical evidence from a seven-year longitudinal study and quasi-ethnographic work, we explore changes in power relations at the different stages of the disaster and longer-term recovery as well as the conditions that fostered these changes. Our findings show distinct patterns of change. First, disasters can trigger long-lasting changes that challenge historical patriarchal relations. Second, while vulnerability increases following a disaster, resilience can potentially counteract women's vulnerability. We propose that resilience can be a pathway to produce long-term changes in gender relations and empower women in the context of disasters.
\end{abstract}

Keywords Gender · Social change $\cdot$ Disaster $\cdot$ Resilience $\cdot$ Vulnerability

\section{Introduction}

The importance of gender in the response to and recovery from disasters has been recognised as a priority by many humanitarian organisations. The Sendai Framework for Action recognises the critical role of women in managing disaster risk and promoting gender-equitable policies (UNISDR 2015). The proliferation of guidelines and toolkits suggests that the gender perspective is successfully integrated into disaster management plans (e.g. ADB 2015; IFRC 2010; Oxfam 2011). However, gender mainstreaming in

Jenny Moreno

jenny.morenoromero@manchester.ac.uk

Duncan Shaw

duncan.shaw-2@manchester.ac.uk

1 Alliance Manchester Business School, The University of Manchester, Manchester M1 3BB, UK

2 Alliance Manchester Business School, Humanitarian and Conflict Research Institute, The

University of Manchester, Manchester M1 3BB, UK 
response to climate change and disasters is in its infancy-more rhetoric and aspirations than action and practice (Bradshaw and Fordham 2014; UN Women, 2016). The lack of theoretical analyses of gender in disaster literature is an additional challenge for genderresponsive policies. Although the word "gender" features frequently, interpretations are simplistic, with "gender" simply referring to women and not to the complex power relations in societies (UN Women 2016). Social and environmental changes, along with cultural and patriarchal systems of power, have meant that disasters engender disproportionate impacts on women (Cutter 2017). Gender norms influence how well households can adapt to change, including changing climate (Perez et al. 2015). However, countries are yet to fully integrate gender issues in an integrated and systematic manner into their climate change and disaster risk reduction (DRR) interventions (UN, 2016).

In the gender and disaster literature, dual themes predominate-women as vulnerable or resilient in relation to the environment (Arora-Jonsson 2011) with less interest in the interaction between them. In this context, we understand vulnerability as "the characteristics of a person or group such as gender, age, ethnicity, disability, and socioeconomic status, and their situation that influence their capacity to cope with, and recover from the impact of a hazard" (Wisner et al. 2004, p 11). Therefore, it is a social condition, partially the product of social inequalities, that create the potential for some people or groups to be more vulnerable than others (Cutter et al. 2003; Wisner et al. 2004). Vulnerability studies often portray women as passive, helpless victims, lacking agency (Bradshaw and Fordham 2013), a portrayal supported by evidence that women are more vulnerable to hazards than men (Dhungel and Ojha 2012; Drolet et al. 2015; Horton 2012). For example, disasters (and their subsequent impact), on average, kill more women than men (Neumayer and Plümper 2007). In a 1991 cyclone in Bangladesh, female mortality was higher than male in most age groups (IKEDA 1995). The incidence of gender-based violence-including rape, human trafficking and domestic abuse-also increases during and after disasters (Alston 2013; UNDP 2010). However, these vulnerabilities are not the result of disasters themselves; they relate to pre-existing social inequalities (Horton 2012), which explain the root causes of gender vulnerability such as unequal political, economic, social and cultural practices (Dhungel and Ojha 2012; Fulu 2007; Gaillard et al. 2015). Therefore, women are not vulnerable because they are weaker; their restricted access to assets (physical, financial, human, social and natural) and unequal power relations are pivotal in undermining their capacity to respond (Bradshaw and Fordham 2014; Smyth 2009). Disasters therefore present an opportunity to challenge gender disparities (Alston 2013; Drolet et al. 2015), but less is known about the extent to which disasters foster progressive change or under what conditions this can occur (Pacholok 2013).

While research on disasters explores women's vulnerability, women's resilience is less documented. Cutter et al. (2008) define resilience "as the ability of a social system to respond and recover from disasters" (Cutter et al. 2008, p 599). Resilience is an inherent (Landau 2007) and a latent (or potential) capacity to respond to future disasters (Boyd et al. 2008). This means almost everyone has some capacities for resilience (Wisner et al. 2004); however, not everyone can activate them due to limitations of access to, and mobilisation of, resources in responding to a disaster (Birkmann et al. 2013). In operational terms, resilience involves those adaptive capacities that lead to a positive functioning after a disturbance (Norris et al. 2008). In post-disaster contexts, social resilience has been observed in adaptive capacities such as participation (King 2007), social capital (Aldrich 2012), leadership (Shaw and Goda 2004), cooperative action (Bhandari 2014). The notion of improvement and positive outlook in which resilience is conceived (Aguirre 2006; Landau 2007) implies that transformative changes are possible. Women's resilience has 
become the mainstream discussion of gender and disasters (Wisner et al. 2016). Relief agencies and scholars advocate for the recognition of women's needs as well as their strengths and assets. Resilience emphasises that women are not merely passive recipients of aid; they are active agents (Gaillard et al. 2015; IFRC 2010); and studies show the crucial role played by women in caretaking, communicating risks, organising communal activities and building new partnerships (Dhungel and Ojha 2012; Shah 2012). Drolet et al. (2015) studied how a small group of women spontaneously organised support to migrant communities in response to hurricanes in 2004 and 2005. Similarly, Gaillard et al. (2015) recounted the collective actions carried out by women after Hurricane Mitch struck Honduras in 1998-organising rescue boats and becoming leaders of the emergency committee. However, despite the recognition of women's resilience, a research gap still exists regarding how this resilience can help to reduce women's vulnerability in the longer term.

Disasters are spaces in which both vulnerability and resilience are revealed. By studying the changes in gender relations in a fishing village affected by the 2010 Chile earthquake and tsunami, we conduct a longitudinal investigation of how vulnerability and resilience is manifested through all stages of the disaster, aspects that have scarcely been studied from a gender perspective. We provide insight into the changes that disasters stimulate in the long-term and how resilience can contribute to reducing women's vulnerability, becoming the pathway for transformative empowerment. This paper addresses these issues by first introducing the theoretical considerations and then explaining the data collection methods and analysis. The findings from the data are provided, leading to a discussion of the study's theoretical contributions.

\section{Disaster and social change}

In disaster scholarship, Bates and Peacock (1987) define social change as an alteration in the structure of the social system, which affects its functioning. Theorising change has been studied (e.g. Nigg and Tierney 1993; Quarantelli 1994), and there is evidence that disasters contribute to change in social, political and economic structures. However, these studies tend to focus on short- or medium-term impacts, not long-lasting change and it is unclear what the catalysts for change are and the extent to which disaster-related disruptions result in progressive shifts in social relations (Pacholok 2013). Challenges also pertain to understanding the nature of change beyond the positive/negative dichotomy. Disaster policy and research have emphasised a positive perspective of change by introducing the principle of "build back better" (UNISDR 2015) for improving pre-existing patterns of vulnerability after disasters (Clinton 2006; Mannakkara and Wilkinson 2014). Manyena et al. (2011) bolster this with the concept of "moving forward" to enhance postdisaster recovery. However, recovery does not always result in positive change; disasters exacerbate social inequalities (de Wall 2008) - poor people are two times more exposed to disasters than non-poor (Kim 2012). Furthermore, vulnerable groups such as children, the elderly, women and people with disabilities can be severely worse off when disaster strikes. An integrative approach is proposed by Norris et al. (2008), who suggest that postdisaster functioning is not necessarily superior in level, character or effectiveness to preevent functioning; it is simply different.

Drawing on the notion that disasters might trigger changes in communities, the interaction between vulnerability and resilience provides insights to the nature and type of post- 
disaster transformations. Disaster scholars have offered theoretical models to understand the process in which resilience-vulnerability interactions occur: For instance, in the DROP model, resilience and vulnerability are seen as antecedents or inherent conditions of communities that overlap; thus, they are not mutually exclusive, nor totally mutually inclusive (Cutter et al. 2008). This aligns with Paton et al. (2000) that vulnerability and resilience need not be discordant. Conversely, in Norris' model (2008), resilience and vulnerability are mutually exclusive processes that lead to adaptation or persistent dysfunction, respectively. Notwithstanding such disagreements, there are more points of convergence than divergence in vulnerability and resilience research (Adger 2006).

Vulnerability can be countered by people's resilience to resist, avoid, and adapt to the processes that generate vulnerability (Wisner et al. 2004). However, there are conflicting explanations regarding how resilience can trigger enduring change, and how it can help reduce women's vulnerability and facilitate their empowerment. Resilience is often evaluated by the amount of change a system can undergo, for example, how much disturbance or stress it can absorb (Turner et al. 2003). Consequently, it is seen as the process of change. Cutter et al. (2008) note that resilience includes "adaptive processes that facilitate the ability of the social system to re-organise and change, and learn in response to a threat" (p 599), suggesting that resilience is a trigger of social change. Adger (2006) argues that adaptation does not necessarily entail changes in system boundaries in building resilience and that any change may not be positive. As Prince (1920, p 22) notes, "change does not necessarily mean progress". A variety of disaster settings such as event characteristics, coping responses (Norris et al. 2008), the sociopolitical and economic landscape (Pacholok 2013) and the multi-dimensionality of change may lead to contradictory patterns of change, defying the simple positive/negative categorisation (Morrow and Peacock 1997).

\subsection{Gender and change}

Disasters can trigger changes in gender relations, but the conditions under which these changes are made possible, their nature, duration and temporality, remain unclear. Theoretical work in this area is limited. The variety of settings and factors involved in a disaster may produce changes in one context but not in another (Davis 2005). In gender relations, norms play a crucial role in defining what constitutes change (Attanapola 2004). For instance, the emergence of new female leaders may not be seen as a change in contexts where women have historically led communities. Conversely, the same leadership can be interpreted as a social change in a patriarchal culture. Disasters can change power relations for better or worse. Yet, there are conflicting explanations regarding whether disasters unleash short- or long-term changes. Some scholars suggest that disasters can produce minimal long-term changes, while others argue that disasters have the propensity to promote major social alterations (Morrow and Peacock 1997; Prince 1920). Others suggest that disasters do not cause significant social transformations but simply speed up or slow down pre-existing trends (Oliver-Smith 1986).

The perspective that has been widely accepted is that disasters do not cause major social changes but accelerate pre-existing patterns of women's vulnerability. According to Cutter (2017), major social changes such as income inequality, gendered violence and large-scale population movements have increased gendered vulnerability to disaster risk over the past two decades. However, the impact of these transformations may remain invisible due to the lack of sex- and age-disaggregated data (Mazurana et al. 2011) which hides the differential burden of disasters on women (Cutter 2017). Bradshaw and Fordham (2013) note that even the emergency events database (EM-DAT) does not disaggregate by gender. Despite this, 
women's vulnerability is exacerbated during and after disasters: women experience unequal access to resources and relief assistance (IFRC 2010; Shah 2012). For example, women may be forced into "transactional sex" to gain access to food and other basic goods during emergencies (Bradshaw and Fordham, 2014), while domestic violence and rape may increase post-disaster (Enarson et al. 2007; Pittaway et al. 2007). This is aggravated by the inadequate design of shelters, which do not assure women's privacy and safety (Fulu 2007; IFRC 2010). Furthermore, poor sanitary conditions in shelters pose physical and mental health risks to women (Bradshaw and Fordham 2013; UN Women 2016). Women's sexual and reproductive health may also be neglected, leading to unplanned pregnancies and sexually transmitted diseases (Bradshaw and Fordham 2014; IFRC 2010) and lower life expectancy for women (Neumayer and Plümper 2007). Women experience additional burdens as caregiving roles and responsibilities at home may increase post-disaster (Enarson et al. 2007). The so-called triple burden may worsen vulnerability as women assume multiple roles, including reproductive, community management and productive roles (Moser 1993). These vulnerability trends reflect the "double disaster" or secondary impacts that women and girls suffer following a disaster, and "these impacts may be the real disaster for women and girls" (Bradshaw and Fordham 2013, p 13).

Changes in women's resilience are an under-explored area of research. Disasters may bring opportunities to reduce women's vulnerability by changing unequal gender regimes, but the contribution of resilience remains unclear. Bradshaw (2013) notes that disasters are "windows of opportunities" ( $p$ 184) to work towards gender equality as they may disrupt processes that reproduce gender roles, creating spaces for women's empowerment (Horton 2012). Nevertheless, changes in these roles may be temporary, and gender inequalities may be re-established after the disaster (Pacholok 2013). The activation of women's grassroots movements following a disaster suggests that fundamental social changes can occur (Enarson and Chakrabarti 2009) and that women's resilience can play a crucial role in it. Case studies show that organised grassroots women have been engaged in relief and recovery efforts. Enarson et al. (2007) show that "this demonstrates the effectiveness of women's grassroots actions, despite limited resources and initial, external opposition in some situations" (p 138). Following the Haiti earthquake, Horton (2012) found new networks of women were formed in response to the limited assistance available. Horton also notes that women do not initially mobilise around women's rights but, instead, around basic needs. Therefore, positive changes in gender relations may be evident in the early stages of a disaster, but it is not clear whether these can be transformative in the longer term. Longitudinal studies contribute to understanding the long-term impacts on gender dynamics (Pacholok 2013), but few exist. These issues lead to the following research questions: what changes in gender relations can emerge following disaster? How does resilience contribute to reducing women's vulnerability in the long term? What conditions are needed for promoting long-lasting changes in gender relations following disaster?

\section{Study site, design and methods}

\subsection{Case selection}

Our research questions on long-lasting social change direct us to a longitudinal study. We choose a single case study strategy which is appropriate when aiming to track over time a contemporary phenomenon within a real-life context (Yin 2003). People's lived 
experiences in different time periods enable us to understand social changes, the hidden meanings of gender relations and how participants made sense of these changes (Grbich 2013). A single-case approach was suitable as the nature of our case is unique (Yin 2003), not only from the significant changes in gender relations but also the survival story of the case.

The selected case is El Morro, a fishing village dating back more than 100 years, standing in the Talcahuano region on the south-central coast of Chile. This is one of the poorest communities in the region and one of the most affected by the 2010 Chile earthquake and tsunami. It consists of around 180 families and a population of over 600 . Fishermen in El Morro have developed small-scale fishing practices, and the majority work as artisan fishermen, representing one of the most vulnerable economic groups in Chile due to precarious working conditions. The devastating tsunami waves in 2010 completely destroyed the houses, fishing boats and equipment in the community, but no casualties were reported as people quickly evacuated to the nearest hill after the earthquake. This is the only community in the region in which all residents survived the tsunami's impact. Following the disaster, people had to live in emergency tents and temporary houses for more than four years before new permanent dwellings were built. This disaster was a turning point, bringing radical change in the social structure and gender relations.

\subsection{Data collection}

The community was studied through the response and recovery phases of the disaster across 7 years (2010-2017), including a variety of data collection methods across different time periods (see Table 1). Our study relied on multiple sources of evidence (Yin 2003), employing different methods, including semi-structured interviews, a focus group discussion, direct observation, document and social media analysis. The collection of different data enabled triangulation to increase validity (Aaltio and Heilmann 2010).

The data were generated from 54 semi-structured interviews with residents, municipal officials, NGO practitioners and relief workers (averaging $1 \mathrm{~h}$ and $32 \mathrm{~min}$ each); four semi-structured interviews with female community leaders (averaging $2 \mathrm{~h}$ and $27 \mathrm{~min}$ each); one focus group with seven members of a grassroots women's organisation ( $3 \mathrm{~h}$ ); field observations (from 11 months of encounters that varied from a few minutes to over $3 \mathrm{~h}$ ); and documents and social media accounts. The 44 female and 21 male participants were identified through a snowball method (Babbie 2004) and by spending time with the community. The semi-structured interviews focused on topics dealing with the impact of the event and coping strategies, and the interview guide was adapted during the research process to include new topics suggested by the participants (Flick 2009). In the postdisaster period, four semi-structured interviews were conducted with women leaders to cover only gender issues in greater detail. The aim was primarily to gather opinions, facts and stories from expert "insiders" (Coombes et al. 2008). A focus group was conducted with a women's organisation to discuss its role and the challenges and opportunities from the disaster. The interviews and focus group were conducted in the homes of the informants, in a comfortable and friendly setting where they could openly share their experiences. All interviews were recorded and transcribed.

Direct observation complemented all the elicitation stages of the fieldwork, with field notes being taken during observation and following field visits. We used a flexible approach during the observation, which allowed us to remain responsive to the process (Flick 2009) and to accommodate aspects not covered by the interviews, including routines, social interactions, traditions and physical artefacts. Informal conversations occurred 
Table 1 Longitudinal data collection process

\begin{tabular}{|c|c|c|c|}
\hline Period & $\begin{array}{l}\text { Length of fieldwork } \\
\text { (months) }\end{array}$ & Data collection methods & $\begin{array}{l}\text { Number of } \\
\text { participants }\end{array}$ \\
\hline 2010 & 1 & $\begin{array}{l}\text { Direct observation, semi-structured interviews and } \\
\text { social media analysis }\end{array}$ & 4 \\
\hline 2013 & 2 & $\begin{array}{l}\text { Semi-structured interviews, direct observation and } \\
\text { document analysis }\end{array}$ & 17 \\
\hline 2014 & 5 & $\begin{array}{l}\text { Semi-structured interviews, direct observation and } \\
\text { focus group }\end{array}$ & 35 \\
\hline 2016 & 2 & $\begin{array}{l}\text { Semi-structured interviews, direct observation and } \\
\text { document analysis }\end{array}$ & 6 \\
\hline 2017 & 1 & Semi-structured interviews and direct observation & 3 \\
\hline
\end{tabular}

naturally during the observations-what Barbour (2014, p 156) calls "incidental ethnographic encounters" (Luton 2015). Documents also helped, including newspapers, social projects, surveys and community diagnoses carried out in El Morro. Documentation and social media were used to collect data about the pre-disaster condition, which was not directly observable. Social media, particularly Facebook and YouTube, were important sources of data about life in El Morro before the disaster, as most of the paper reports and material documentation, including pictures, were destroyed by the tsunami.

\subsection{Data analysis}

The analysis took an inductive approach to discover patterns of change from the perspective of participants (Babbie 2004). The data were collated as transcripts, field notes, documents and social media accounts, and a rigorous qualitative coding strategy of these discovered meanings and patterns of relationships (Braun and Clarke 2013). Our data analysis procedure followed three steps. First, we applied an open coding process in which we segmented the data into broad concepts (Corbin and Strauss 2008). Similar codes were then grouped around categories. We developed these categories further by ordering them by time- - which helped to eventually discover five stages of the disaster from the data: predisaster, immediate emergency, emergency, recovery and post-disaster. Second, we refined our categories by conducting axial coding. This identified and classified links between the categories which led us to find patterns of similarities and differences across the data. Assumptions about change and gender relations were questioned and explored, leading to new discoveries (Corbin and Strauss 2008). To find and build confidence in these patterns of change, methodological triangulation (Denzin 2009) and triangulation of sources (Ritchie et al. 2013) proved helpful. The last step involved the development of a selective coding which enabled us to identify the themes across all the data leading to theory generation and formulating the story of the case (Flick 2009). 


\section{Findings}

The findings are presented according to the five stages. These stages were found to correspond to changes in the living conditions as well as the short- and long-term changes in power relations. Findings show how vulnerability was intensified after the disaster and how resilience contributed to lessening gender vulnerability. Below, each section first contextualises the period and then presents the main themes found in that period. Quotes from the interview transcripts illustrate the themes, and pseudonyms are used to safeguard participants' anonymity.

\subsection{Pre-disaster (before the earthquake and tsunami)}

\subsubsection{Traditional gender roles, top-down approach and early resilience}

This period was characterised by women's vulnerability as an expression of traditional gender roles, lack of participation and limited access to resources. Women's position in the community remained "invisible", while men's position was recognised and "visible"-a feature reinforced by the Municipal Government. El Morro had a strong patriarchal structure before the disaster. Fishing was an exclusive male activity supported by historical patterns of generations working in the sector. Therefore, men assumed the role as the family's breadwinner, while women assumed the reproductive role. The women recounted that they were confined to the domestic space and were responsible for looking after children, cooking and cleaning. Patricia, a mother of three, recalled her normal routine: "I was most of the time at home, doing chores, cleaning, washing and cooking. I did food shopping in the morning, and in the afternoon, I would pick up my children from school. In the evening, I prepared the dinner for my family".

Women's community management role was restricted by exclusion and patriarchy. Participants reported that there were three community organisations, all led by men: El Morro Neighbourhood Council, El Morro Football Club and El Morro Fishermen's Union. Female interviewees perceived that women's needs and voices were overlooked as their participation was restricted to small organisations managed by the Talcahuano Municipality, e.g. providing 1-year training in sewing, crafting and cooking. Although these groups reinforced traditional occupations and gender stereotypes, they were not perceived as gender constraints by the participants. Likewise, the top-down approach imposed by the municipal government in selecting this training was not identified as an obstacle. Women accepted this fact as something "natural". Norma, a mother of four, said: "this is what women normally do, and they can easily learn".

A different situation was observed in a women's group called "Palomitas Blancas", which was composed of 12 middle-aged women who were the wives of fishermen and was formed in 2004 following the Chile fishermen's crisis. Pamela, a mother of three, reported on the role of this organisation: "We wanted to contribute to the subsistence of our families, and we carried out fundraising events. We cooked typical Chilean food and sold it to our neighbours". Although the scope of this group was limited, it is an early example of women's resilience counteracting their unequal economic conditions by assuming an early productive role. 


\subsection{The immediate emergency (27 February 2010-5 March 2010)}

\subsubsection{Gendered evacuation, absence of external aid and community kitchens}

This period was characterised by the survival in El Morro and the absence of external help in the days following the disaster. Vulnerability was accentuated by the tsunami's decimation of houses and fishermen's livelihoods as well as widespread looting in the aftermath, which threatened safety. The evacuation process and coping strategies were gendered. Most interviewees reported that men took charge of rescue and relief operations, while women looked after their children. Therefore, men took the role of "heroes" or "rescuers", while women were the "rescued" or "victims". Rafael, a 58-year-old fisherman and father of five, gave an account of the men's search and rescue actions: "We saved women who were alone because their husbands were on the high seas. We rescued a pregnant woman from the window and elderly people who could not move on their own".

Changes in gender relations were minimal at this stage, as men and women accepted traditional gender roles following the evacuation, the need for food and water triggered other gendered tasks. Men took the role of "providers" by collecting food, blankets and medicines and being responsible for the safety of the community, taking the role of "protectors". Juan, a 55-year-old fisherman, said: "We organised security guards to defend our community from looting and vandalism; we needed to protect our families". However, women's domestic and community management roles changed in this period as their resilience expanded. Women recalled that they spontaneously expanded their skills from a domestic/household level to a community level by creating a community kitchen and "Palomitas Blancas" took new responsibility for allocating the scarce resources collected by men. Elena, a "Palomitas Blancas" member, described: "Before the earthquake, we worked for the maintenance of our own families, and during the emergency, we had to prepare provisions for 170 families". This was an opportunity to make women's domestic role more visible and change their vulnerable position of housewife to a more active community role which increased women's perception of self-value. As Lily, a mother of two, recounted: "People appreciated what we were doing; we were helping our community; I felt important".

\subsection{Emergency (March-June 2010)}

\subsubsection{Vulnerability, leadership and women's organisation}

In this period, both vulnerability and resilience increased as well as women's community management role. However, patriarchal relations sought to impose restrictions, as women's increased empowerment took hold. Vulnerability was exacerbated by the precarious conditions of the emergency camps installed by the government during this period. The cold weather led to outbreaks of infectious diseases and winter-borne illnesses. Women's sexual and reproductive health was neglected, leading to unplanned pregnancies and miscarriages. Andrea, a housewife and mother of two, recalled: "There were two women who did not know they were pregnant until they lost their babies when they were carrying heavy buckets of water from the hill". The lack of privacy in tents impacted the mental health of women and men, causing stress and depression. While women continued with the reproductive role in the domestic space, men lost their productive role as the tsunami destroyed their sole source of livelihood. At the community level, men also lost 
participation spaces as traditional male organisations, including El Football Club and El Morro Fishermen's Union, were inactive. Carlos, a fisherman and father of three, said: "I feel helpless, I do not have a job, money and a house. I feel so frustrated, I cannot buy school uniforms for my children and give money to my wife".

Women increased their presence at the community level, as their management skills expanded. Resilience emerged more strongly in this period to deal with the vulnerable conditions of the camp. Women's grassroots groups and female leadership played a crucial role in countering women's vulnerability. Regarding grassroots groups, "Palomitas Blancas" established three community kitchens, instead of one, to improve efficiency, and the organisation increased in size. Although the primary focus was the satisfaction of basic community needs, the organisation was also a "therapeutic hub" for women-an intimate space for sharing women's experiences, feelings and comforting one another. Claudia, a mother of three, said: "we listened to each other, and we cried together". Nonetheless, patriarchal relations were imposed during this period, with female respondents recounting that this space was not understood by men, who verbally abused women and stigmatised them as "gossipers".

Leadership was another nascent characteristic of women's resilience in this period. Maria, a member of "Palomitas Blancas" and a mother of two, emerged as a leader. She led the community kitchen and restored order in the community after the tsunami. According to Andres, a municipal officer who was interviewed, the formal male leader of the El Morro Neighbourhood Council, Cristian (a 58-year-old fisherman), could not control the crisis and manage the humanitarian aid received. Maria could calm people and give hope during the difficulties. Juana, a mother of three, recalled: "Maria was emotionally involved with people, and her strength and positive attitude gave us a sense that everything was under control". However, Maria's perception was different. She reported being afraid and lacking in confidence: "I was afraid, but I had to make myself strong. My people needed me". Felipe, an NGO practitioner, informed that Maria's social skills, commitment and eagerness to help, enabled through the community kitchen, contributed to her empowerment. Maria's internal resilience was the trigger for the activation of her external resilience. She explained: "I wanted to help because I always liked helping people, especially the elderly. I also knew that if I had not done something, there would have been chaos... I did not like the way the previous leader was distributing the food; I saw unfair things, so I decided to intervene and help" (Maria, 48-year-old interviewee).

Maria was quickly recognised throughout the country, while the previous (male) leader took a passive role. For the first time, women were more visible than men in the community, but despite Maria's growing popularity, traditional gender relations were reestablished. At the end of this period, during the election of members of the Neighbourhood Council, Maria received the majority of electoral votes, with Cristian coming second. Ana, a female member of the Neighbourhood Council, informed: "the assembly decided that Cristian would continue to be the president despite not having received the majority of votes and that Maria would assume the role of vice-president. We wanted to respect Cristian's experience and knowledge". Thus, the power of patriarchal relations prevailed over Maria's popularity, which hindered the change of formal community leadership. 


\subsection{Recovery (July 2010-May 2014)}

\subsubsection{Multiple burden, bouncing back and moving forward}

After 6 months of living in tents in the emergency camp, the government refused to reconstruct El Morro in the same place. People were offered to move far away from the beach, which posed a threat to fishermen's livelihood. The government provided small, temporary houses that could not resist the wind and humidity of the coast. The precarious living conditions caused overcrowding, exacerbating physical and mental problems. Eliana, a mother of two, said: "This was the most difficult period for us; we were in a crisis". Permanent housing was promised but delayed for 4 years, generating conflict in the community. The Municipal Government's top-down approach brought changes in community functionality and power relations, and as gender roles continued to change, the disaster recovery evolved, and resilience and vulnerability manifested in a conflictive relationship.

The disruption in the productive role of men was short-lived, as men recovered their position, receiving new boats from humanitarian aid. Consequently, the community kitchens dissolved, as families bought their own stoves to prepare meals. Women's productive role reverted to the domestic space which meant that "Palomitas Blancas" no longer had a significant role. Lidia, a member, recounted: "We decided to continue doing what we did before the disaster. We met every week at the house of one of our members, sharing stories, laughing, cooking and carrying out internal fundraising". Thus, the expansion of this women's organisation was transitory, reverting to the pre-disaster state.

Despite the contraction of "Palomitas Blancas", women's resilience continued to develop through Maria's leadership. Even though Maria was not the formal President of the Neighbourhood Council, she was considered by many as the community's representative. This was a major change which challenged the history of male-only community leaders. Maria was able to put her management skills to demand the government the reconstruction of the houses in the same land which was finally granted, bringing relief to the entire community. Nonetheless, Maria's leadership faced major challenges in this period. She endured verbal abuse from neighbours, especially men, due to delays in the reconstruction and the relocation threat from the government. She reported that she had to build a strong character to defend herself: "Men were shouting at me in the corner, swearing at me. I had to learn how to defend myself, and I shouted them back. I needed to do that so that they would learn to respect me". She changed her "caring" leadership style to an authoritarian one. Furthermore, she recounted being overwhelmed by the many roles she had to simultaneously undertake. The kitchen apron became the symbol of the multiple burden. As she described: "I was a housewife, leader, mother, social worker, nurse, psychologist... I had to attend to my family's needs as well as the problems of my neighbours. I had a 24-h shift without rest. People were coming at 1:00 am, 2:00 am and 3:00 am asking for help. I was so tired that I had to put a notice on my door, telling people 'please, do not disturb' or 'I'm not at home'. In all TV interviews, you can see me wearing a kitchen apron, but my friends were always saying to me: 'Please take it off, you are on the TV!' But I refused to do so because I wanted to show the real me, and I also did not have time to change my clothes...I love my kitchen apron because I can do many things at the same time. I can cook, clean the house... in one of the pockets, I keep my phone and in another a small notebook and pen for taking notes when someone calls me. It is so useful". The recovery period ended with housing reconstruction in the same land but with a 
profound emotional wear on women. Patriarchy was imposed strongly in this period, but Maria's inner resilience, her strong leadership and the women's support networks sustained women's empowerment in the community.

\subsection{Post-disaster (May 2014 to present)}

\subsubsection{Long-lasting changes, women's rights and productive role}

Seven years after the disaster, radical transformations in gender relations have changed the historical patriarchal patterns. Women's resilience strengthened over time by the expansion of women's community management role and female leadership that contributed to reducing the unequal gender relations in the community, breaking historical patriarchal regimes. Women have been empowered socially, politically and economically.

Maria is still the deputy of the Neighbourhood Council-a long-lasting change. In the previous stage, her leadership was driven by the necessity of food and shelter, but as those needs were covered, new interests emerged. She now focuses on implementing social projects for children, women and the elderly. The most remarkable action was the government granting the legal title of new permanent houses to women to protect their rights. This is the only community in Chile in which women are the only homeowners in a single community. This shows that although women's actions during disasters are not initially motivated by women's rights, such developments are possible. Maria explained: "I wanted to protect women in case men abandoned them, abused them, or cheated on them... now, women are safe because they are the owners of their homes".

Another important transformation arose in women's productive role. An emergent women's organisation was spontaneously formed in 2015: El Morro Fisherwomen. This organisation gathered the housewives of approximately sixty fishermen who wanted to contribute to the family income through fishing and the collection of seaweed and mussels, which constituted a new practice. This is a crucial change in El Morro as fishing was an exclusively male activity before the disaster. The leader of this organisation is Antonia, a 47-year-old mother of twins who had never before performed a community role. She reported that despite her lack of confidence, her willingness to help and the support of other women, especially Maria (the deputy of the Neighbourhood Council) have slowly empowered her. In her words: "I am much better than when I started. Maria has helped me to gain more self-confidence, and her experience is very useful for me". The transfer of women's experiences and knowledge has been crucial in encouraging the renaissance of new female community leaders in promoting resilience.

The disaster not only changed the economic role of women but also contributed to an upsurge in women's activism. The Fishermen's Union, an organisation led by men since 1941, is now led by a woman. Maria continues to be the deputy of the Neighbourhood Council, although she is recognised and acts as the formal president. "Palomitas Blancas" continues as a community organisation, performing its pre-disaster activities. The El Morro Football Club is the only surviving male-only organisation in the community. Over a period of 7 years, women have moved from being passive victims to active agents of change, contributing economically, socially and politically to the community's development - a radical change that has empowered women and improved their position in the community. 


\section{Discussion}

Social change and disasters is an area ripe for research. Conflicting explanations of whether disasters may or may not induce social change, coupled with a lack of longitudinal studies, have restricted theory development in this area. Our findings expand current understanding by observing long-term changes in gender relations, filling a fundamental gap in the literature. The changes in El Morro unveil the crucial role played by resilience in reducing women's vulnerability. We propose that resilience can be the pathway to produce longterm changes in gender relations and empower women in the context of disasters.

\subsection{Gender and change}

Regarding our first research question: What changes in gender relations can emerge following disaster? Our longitudinal research allowed us to observe the changes in gender relations over a period of 7 years. Disasters can create conditions that facilitate social change as our case showed. However, claiming that the changes in gender relations in El Morro were exclusively caused by the disaster is not possible due to social changes being facilitated by multiple variables such as the sociopolitical environment (Morrow and Peacock 1997; Norris et al. 2008) and other factors from gender vulnerability scholarship (such as race, class, place and culture) may also have affected the social change (Ajibade et al. 2013; David and Enarson 2012). Despite all possible variables that could have had affect, according to participants, the disaster was the main trigger of social change. The qualitative nature of our research also allowed us to observe the changes that were more meaningful for people after the disaster. This led us to find the patterns of change: while vulnerability is exacerbated after the disaster, our study showed that resilience emerges as an adaptive capacity that counteracts women's vulnerability.

We found that the changes in gender relations in El Morro were characterised by contradiction, which is an expected outcome given the variation in social systems (Pacholok 2013). Contrary to the position that disasters may only trigger minor and short-term changes (Wright et al. 1979), our findings align with the classic work of Bates and Peacock (1987) and Prince (1920) that lasting social changes from disasters are possible and can facilitate major transformations in social structures. Gender roles and norms do change, sometimes very quickly following disaster (Perez et al. 2015, p 106). Long-term changes were observed as a transition in gender roles from the emergency to the post-disaster period. During the immediate emergency, traditional gender roles predominated as women assumed caregiving duties, housekeeping and emotional work, which is in line with other studies (Ajibade et al. 2013; Attanapola 2004). Although women's roles are usually less visible and men's disaster work is more visible in this phase (Ajibade et al. 2013; Horton 2012), our research shows that women's roles can become visible when the domestic role is extended to the community level (community kitchens in El Morro). The disaster diffused the boundaries between the private and public spaces, which enabled opportunities to recognise women's domestic leadership.

Women's contribution plays a key role in reducing the impact of environmental degradation (Fatma 2002). Our study indicates that women's community management role endured structural transformations. Women moved from low-community involvement to high involvement, which still prevails today. Therefore, the disaster was an opportunity to challenge historical patriarchal relations (Cupples 2007; Fordham et al. 2006). The changes in gender roles empowered women and upgraded their position in the community- 
transitioning from a passive role of "victims" and "rescued" during the immediate emergency to the role of "active agents" during the recovery and post-disaster.

\subsection{Resilience as a pathway to produce long-term changes}

Regarding our second research question: how does resilience contribute to reducing women's vulnerability in the long term? Our findings suggest that disasters exacerbate existing vulnerability-which coincides with Morrow and Peacock (1997). Disasters can exacerbate existing inequalities between women and men and intensify gendered experiences of poverty (Demetriades and Esplen 2008). The case shows how patriarchal relations imposed during the emergency and recovery intensified patterns of aggression. However, resilience counteracted women's vulnerability by the activation of female leadership and women's grassroots groups. The emergence of grassroots women's groups was essential to keep the process of women's empowerment throughout all stages of the disaster. Therefore, our findings confirm that women's grassroots movements can bring important changes to communities (Enarson 2012) and that disasters create opportunity for this. Furthermore, the emergence of a key leader in heightening the role of other women and this leader pushing through wider social impacts in a male-dominated community was also crucial to reduce women's vulnerability to disaster. Thus, resilience acts as an adaptive capacity which can facilitate the social system to reorganise, change and learn (Cutter et al. 2008).

Women's resilience reflected in leadership and grassroots organising (Enarson 2001) showed its potential to bring long-term changes. Women were able to build more participation spaces and influence decision-making processes-spaces that are usually restricted from women during disasters (Dhungel and Ojha 2012). Although Enarson (2001) found that opportunities for non-traditional work during disasters may be short-lived and should not be exaggerated, our findings demonstrate the contrary. The emergence of fisherwomen during the post-disaster period reveals that resilience can trigger changes in women's productive role in the long term. Therefore, resilience allowed a progressive transformation of women's position in the community, as these women gained more spaces in the social, political and economic spheres. We call this progressive shift transformative change.

Drawing on principles of structural-functionalism, a system seeks to sustain equilibrium among its components after a disaster (Nigg and Tierney 1993). Returning to a pre-disaster state may be a consequence for communities, but this may only be true to a certain extent. Our findings show that both temporal and permanent changes occur after the activation of resilience. Resilience can emerge as an adaptive capacity that can bounce back or move forward depending on the stage of the disaster. We propose that while short-term changes reflect the resilient ability to bounce back, long-term changes show the ability to move forward. These attributes were observed in the transition of "Palomitas Blancas" to an extensive organisation during the emergency (Dynes 2005) and its eventual return to a predisaster level. However, it is the "moving forward" condition that makes women's empowerment possible, for example, in the development of Maria's and Antonia's leadership.

Women can be simultaneously vulnerable and resilient to disasters, the women's triple/multiple burden being an example (Moser 1993). Women's empowerment in El Morro was possible by taking on more domestic, productive and community roles, which increased their resilience to cope. However, these roles brought new burdens, which may have increased their pre-disaster vulnerability (Enarson et al. 2007). Consequently, increasing resilience does not necessarily bring positive changes in women's conditions. 
Our findings also demonstrate that vulnerability faced by women acted as a catalyst to resilience. The lack of access to resources and the slow emergency response from government and male community leaders motivated women become leaders. As a trigger, vulnerability presents an opportunity to return to the classic view of resilience in which adverse circumstances are a catalyst for positive growth (Werner and Smith 1982). Our research reflects the same principle in a vulnerable context: resilience emerges as an adaptive capacity to challenge unequal gender relations.

\subsection{Conditions that foster changes in gender relations}

It is important to know how and in what contexts women find themselves able to deal reliably with the unequal effects of disaster (Arora-Jonsson 2011). However, the disaster literature fails to specify the conditions that promote social change. Gender relations in El Morro showed that changes can be stimulated by resilience through the activation of female leadership and grassroots women's organisations. El Morro brought important lessons that can orientate policy makers and humanitarian organisations about how to build resilience to counteract women's vulnerability and promote social long-term change. We addressed this challenge through our third research question: What conditions are needed for promoting long-lasting changes in gender relations following disaster?

\subsubsection{Women's leadership}

Maria's leadership encouraged women's involvement in emergency and reconstruction tasks and brought positive changes in women's property rights. Changes in leadership style and adaptive responses are not new (Geier 2016), yet the impact of long-term changes after disasters remains understudied. The caring approach of women's leadership (Ganapati 2012) attenuated the impact of the event (Hannah et al. 2009). Research suggests that women tend to face more challenging environments than men due to traditional gender roles expectations that reduce the attainment of leadership roles (Chaturvedi et al. 2012). On the contrary, men face a more supportive environment, with more access to power and resources for growth in leadership (Ridgeway 1992). Despite women's limitations to entry into leadership, our findings identify two conditions under which female leadership can grow and support long-term change: internal resilience and the "mirror effect".

Maria's personal and social skills unveiled her internal resilience capacity, a potential source for external change. Therefore, an internal (individual) manifestation of resilience can bring changes in external (community) resilience. However, the inability to perceive internal resilience may hamper the likelihood for change. Maria's and Antonia's selfperception of being incompetent in earlier stages of the disaster was not an impediment for change, though it could be in other contexts. Therefore, aid agencies should tackle women's psychological barriers to unfold leadership skills by implementing programmes that build self-esteem and confidence which could encourage women to take on leadership positions.

Our research showed that women are able to influence one another. In El Morro, Maria's leadership was a mirror for Antonia's leadership who projected her self-image through the example of Maria, from whom she learnt how to lead and overcome difficulties. It was the constant interaction and support among these women that allowed learning and mutual empowerment. We call the condition in which change is caused by a reflection of others the "mirror effect". This finding can be useful to promote gender initiatives geared towards enhancing knowledge-sharing among women where the 
experience of leaders such as Maria can be transferred to other women to encourage the emergence of new female leaders.

\subsubsection{Women's grassroots organisations}

Our results suggest two circumstances in which women's grassroots can persist over time, maximising the chances for social change: evolving women's interests and the "ripple effect". Observations in El Morro during the emergency align with Horton's (2012) proposition that women initially mobilise in response to crisis as opposed to women's rights advocacy. This coincides with Twigg (1999) and the idea of communities as problem-solving entities. However, our findings demonstrate that when urgent needs are solved, new women's interests arise such as the right to property observed in El Morro. Thus, advocacy for women's rights can endure, leading to new transformations. We identify this "ripple effect" as those changes which, like ripples, expand and, affect other structures of the community and encourage other changes. In El Morro, the "Palomitas Blancas" organisation brought a new female leader who changed the male-dominated structure of the Neighbourhood Council. The latter encouraged the emergence of the fisherwomen organisation, shifting the economic position of women in the community. Therefore, agencies can use the initial women's agency to raise awareness about women's rights that could lead to actions towards the transformation of unequal power relations in different areas, including social, political and economic.

Breaking unequal gender regimes is a shared responsibility between governments, humanitarian aid agencies and local communities. Our research showed that disasters can be an opportunity to transcend patriarchal power relations by activating women's resilience to disasters. Governments have the primary responsibility for promoting gender equality and building disaster resilience (UNISDR 2009, p 28). This can be done by designing and implementing gender-sensitive policies and programmes at the national and local levels; increasing awareness on gender vulnerability and women's capabilities to deal with disasters; developing gender-based vulnerability and resilience assessments, tools and indicators in partnership with local communities. The overarching aim is to address women's strategic needs and interests (Le Masson 2016) to access equal opportunities, resources and information to challenge patriarchal structures and increase their resilience to future disasters.

\section{Conclusion}

This research shows that disasters can trigger long-term changes in gender relations, even in highly patriarchal contexts. Disasters offer windows of opportunities to challenge unequal power relations through building resilience over time. This can counteract women's vulnerability worsened following disaster. Beyond exploring the possibility of change that disasters offer, we found that women's leadership and grassroots women's organisations were crucial in producing long-term changes. This allowed a women's transformative empowerment manifested in the upgraded social, political and economic conditions of women.

The findings also reveal the conditions that unleash long-lasting changes in gender relations. The internal aspects of leadership and women's organisations led us to suggest that changes can be stimulated "from the inside out" by promoting women's inner 
strengths, mutual learning and collaboration. Investing in building women's resilience both internally and externally can increase their adaptive capacity to climate change and disaster. The challenge is to find points of intervention to increase resilience to future changes, including unforeseeable ones (Perez et al. 2015). This can be encouraged by gendersensitive programmes at the national and local levels that address gender relations from a holistic and multi-stakeholder approach and improve gender equality and women's empowerment.

We were limited by the observation of a single case study; however, we encourage the study of multiple cases to compare longitudinal changes in different settings. This can contribute to finding patterns of similarity and diversity. Finally, more theorisation and empirical research are required to elaborate frameworks.

Acknowledgements We would like to thank the UK Engineering and Physical Sciences Research Council (EPSRC) for the financial support of this research as part of the project EP/N034899/1. We are very grateful to those who participated in the data collection activities, especially to women and men from El Morro, and Talcahuano municipality for supporting this research.

Open Access This article is distributed under the terms of the Creative Commons Attribution 4.0 International License (http://creativecommons.org/licenses/by/4.0/), which permits unrestricted use, distribution, and reproduction in any medium, provided you give appropriate credit to the original author(s) and the source, provide a link to the Creative Commons license, and indicate if changes were made.

\section{References}

Aaltio I, Heilmann P (2010) Case study as a methodological approach. In: Wiebe E, Durepos G, Mills AJ (eds) Encyclopedia of case study research. SAGE Publications, Thousand Oaks

ADB (2015) Training manual to support country-driven gender and climate change. Asian Development Bank

Adger WN (2006) Vulnerability. Glob Environ Change 16:268-281

Aguirre B (2006) On the concept of resilience. Disaster Research Center, University of Delaware, Delaware

Ajibade I, McBean G, Bezner-Kerr R (2013) Urban flooding in Lagos, Nigeria: patterns of vulnerability and resilience among women. Glob Environ Change 23:1714-1725

Aldrich DP (2012) Building resilience: social capital in post-disaster recovery. University of Chicago Press, Chicago

Alston M (2013) Environmental social work: accounting for gender in climate disasters. Aust Soc Work $66: 218-233$

Arora-Jonsson S (2011) Virtue and vulnerability: discourses on women, gender and climate change. Glob Environ Change 21:744-751

Attanapola CT (2004) Changing gender roles and health impacts among female workers in export-processing industries in Sri Lanka. Soc Sci Med 58:2301-2312

Babbie ER (2004) The practice of social research. Wadsworth Publishing Co Inc, Belmont

Barbour RS (2014) Introducing qualitative research: a student's guide. Sage Publications Ltd, London

Bates FL, Peacock WG (1987) Disasters and social change. In: Dynes RR, Demarchi B, Pelanda C (eds) The sociology of disasters. Franco Angeli Press, Milan, pp 291-330

Bhandari RB (2014) Social capital in disaster risk management; a case study of social capital mobilization following the 1934 Kathmandu Valley earthquake in Nepal. Disaster Prev Manag 23:314-328

Birkmann J, Cardona OD, Carreño ML, Barbat AH, Pelling M, Schneiderbauer S, Kienberger S, Keiler M, Alexander D, Zeil P, Welle T (2013) Framing vulnerability, risk and societal responses: the MOVE framework. Nat Hazards 67(2):193-211

Boyd E, Osbahr H, Ericksen PJ, Tompkins EL, Lemos MC, Miller F (2008) Resilience and 'climatizing' development: examples and policy implications. Development 51(3):390-396

Bradshaw S (2013) Gender, development and disasters. Edward Elgar Publishing, Cheltenham

Bradshaw S, Fordham M (2013) Women, girls and disasters: a review for DFID. Report produced for the Department for International Development, UK 
Bradshaw S, Fordham M (2014) Double disaster: disaster through a gender lens. Hazards, risks and disasters in society. Hazards and disasters series. Elsevier, London, pp 233-251

Braun V, Clarke V (2013) Successful qualitative research: a practical guide for beginners. SAGE Publications, London

Chaturvedi S, Zyphur MJ, Arvey RD, Avolio BJ, Larsson G (2012) The heritability of emergent leadership: age and gender as moderating factors. Leadersh Q 23:219-232

Clinton WJ (2006) Lessons learned from tsunami recovery: key propositions for building back better. Office of the UN Secretary-General's Special Envoy for Tsunami Recovery, New York

Coombes L, Allen D, Humphrey D, Neale J (2008) In-depth interviews. In: Neale J (ed) Research methods for health and social care. Palgrave Macmillan, Basingstoke

Corbin JM, Strauss AL (2008) Basics of qualitative research: techniques and procedures for developing grounded theory. Sage Publications Inc, Thousand Oaks

Cupples J (2007) Gender and hurricane Mitch: reconstructing subjectivities after disaster. Disasters 31:155-175

Cutter SL (2017) The forgotten casualties redux: women, children, and disaster risk. Glob Environ Change 42:117-121

Cutter SL, Boruff BJ, Shirley WL (2003) Social vulnerability to environmental hazards*. Soc Sci Q $84: 242-261$

Cutter SL, Barnes L, Berry M, Burton C, Evans E, Tate E, Webb J (2008) A place-based model for understanding community resilience to natural disasters. Glob Environ Change Hum Policy Dimens 18:598-606

David E, Enarson EP (2012) The women of Katrina: How gender, race, and class matter in an american disaster. Vanderbilt University Press, Nashville

Davis D (2005) Reverberations: Mexico City's 1985 earthquake and the transformation of the capital. In: Vale LJ, Campanella TJ (eds) The resilient city: how modern cities recover from disaster. Oxford, New York, pp 255-280

De Wall A (2008) Foreword. In: Gunewardena N, Schuller M (eds) Capitalizing on catastrophe, globalization and the environment. Altamira Press, Lanham, pp ix-xiv

Demetriades J, Esplen E (2008) The gender dimensions of poverty and climate change adaptation. IDS Bull 39:24-31

Denzin NK (2009) The research act: a theoretical introduction to sociological methods. Transaction Publishers, Somerset

Dhungel R, Ojha RN (2012) Women's empowerment for disaster risk reduction and emergency response in Nepal. Gend Dev 20:309-321

Drolet J, Dominelli L, Alston M, Ersing R, Mathbor G, Wu H (2015) Women rebuilding lives post-disaster: innovative community practices for building resilience and promoting sustainable development. Gend Dev 23:433-448

Dynes RR (2005) Community social capital as the primary basis for resilience. Preliminary paper 344. University of Delawere. Disaster Research Centre

Enarson E (2001) What women do: gendered labor in the Red River Valley flood. Glob Environ Change Part B Environ Hazards 3:1-18

Enarson E (2012) Women confronting natural disaster: from vulnerability to resistance. Lynne Rienner Publishers, Boulder

Enarson E, Chakrabarti PGD (2009) Women, gender and disaster: global issues and initiatives. SAGE Publications, Thousand Oaks

Enarson E, Fothergill A, Peek L (2007) Gender and disaster: foundations and directions. In: Rodríguez H, Quarantelli EL, Dynes RR (eds) Handbook of disaster research. Springer, New York, pp 130-146

Fatma D (2002) Climate change vulnerability, impacts, and adaptation: Why does gender matter? Gend Dev 10:10-20

Flick U (2009) An introduction to qualitative research. SAGE Publications, London

Fordham M, Ariyabandu MM, Gopalan P, Peterson K (2006). Please don't raise gender now-we're in an emergency! World Disasters Report International Federation of Red Cross and Red Crescent Societies

Fulu E (2007) Gender, vulnerability, and the experts: responding to the Maldives Tsunami. Dev Change 38:843-864

Gaillard J, Fordham M, Sanz K (2015) Culture, gender and disaster: from vulnerability to capacities. Cultures and disasters: understanding cultural framings in disaster risk reduction. Taylor \& Francis, London, pp 222-234

Ganapati NE (2012) In good company: why social capital matters for women during disaster recovery. Public Adm Rev 72:419-427

Geier MT (2016) Leadership in Extreme Contexts. J Leadersh Organ Stud 23:234-247 
Grbich C (2013) Qualitative data analysis: an introduction. SAGE Publications, London

Hannah ST, Uhl-Bien M, Avolio BJ, Cavarretta FL (2009) A framework for examining leadership in extreme contexts. Leadersh Q 20:897-919

Horton L (2012) After the earthquake: gender inequality and transformation in post-disaster Haiti. Gend Dev 20:295-308

IFRC (2010) A practical guide to gender-sensitive approaches for disaster management. International Federation of Red Cross and Red Crescent Societies

Ikeda K (1995) Gender differences in human loss and vulnerability in natural disaster: a case study from Bangladesh. Indian J Gend Stud 2:171-193

Kim N (2012) How much more exposed are the poor to natural disasters? Global and regional measurement. Disasters 36:195-211

King D (2007) Organisations in disaster. Nat Hazards 40:657-665

Landau J (2007) Enhancing resilience: families and communities as agents for change. Fam Process 46:351-365

Le Masson V (2016) Gender and resilience: from theory to practice. BRACED Working Paper, Overseas Development Institute, London

Luton LS (2015) Qualitative research approaches for public administration. Taylor \& Francis Inc, Armonk

Mannakkara S, Wilkinson S (2014) Re-conceptualising "Building Back Better" to improve post-disaster recovery. Int J Manag Proj Bus 7:327-341

Manyena B, O'Brien G, O'Keefe P, Rose J (2011) Disaster resilience: a bounce back or bounce forward ability? Local Environ 16:417-424

Mazurana D, Benelli P, Gupta H, Walker P (2011) Sex and age matter: improving humanitarian response in emergencies. Feinstein International Center, Tufts University

Morrow HB, Peacock WG (1997) Disasters and social change: hurricane Andrew and the reshaping of Miami? In: Peacock WG, Hearn Morrow B, Gladwin H (eds) Hurricane Andrew: Ethnicity, gender, and the sociology of disasters. Routledge, New York, pp 226-242

Moser C (1993) Gender planning and development: theory, practice, and training. Routledge, London

Neumayer E, Plümper T (2007) The gendered nature of natural disasters: the impact of catastrophic events on the gender gap in life expectancy, 1981-2002. Ann Assoc Am Geogr 97(3):551-566

Nigg JM, Tierney KJ (1993) Disasters and social change: consequences for community construct and affect. Preliminary paper 195. The University of Delaware. Disaster Research Centre

Norris FH, Stevens SP, Pfefferbaum B, Wyche KF, Pfefferbaum RL (2008) Community resilience as a metaphor, theory, set of capacities, and strategy for disaster readiness. Am J Community Psychol 41:127-150

Oliver-Smith A (1986) The martyred city: death and rebirth in the Peruvian Andes. University of New Mexico Press, Albuquerque

OXFAM (2011) Gender and disaster risk reduction: a training pack. Oxfam, Oxford

Pacholok S (2013) Into the fire: disaster and the remaking of gender. University of Toronto Press, Toronto

Paton D, Smith L, Violanti J (2000) Disaster response: risk, vulnerability and resilience. Disaster Prev Manag Int J 9:173-180

Perez C, Jones EM, Kristjanson P, Cramer L, Thornton PK, Förch W, Barahona C (2015) How resilient are farming households and communities to a changing climate in Africa? A gender-based perspective. Glob Environ Change 34:95-107

Pittaway E, Bartolomei L, Rees S (2007) Gendered dimensions of the 2004 tsunami and a potential social work response in post-disaster situations. Int Soc Work 50:307-319

Prince SH (1920) Catastrophe and social change. Political Science, Columbia

Quarantelli EL (1994) Emergent behaviors and groups in the crisis time periods of disaster. Preliminary paper 206. The University of Delaware. Disaster Research Center

Ridgeway CL (1992) Gender, interaction, and inequality. Springer, New York

Ritchie J, Lewis J, McNaughton C, Ormston R (2013) Qualitative research practice: a guide for social science students and researchers. SAGE Publications, London

Shah SA (2012) Gender and building homes in disaster in Sindh, Pakistan. Gend Dev 20:249-264

Shaw R, Goda K (2004) From disaster to sustainable civil society: the Kobe experience. Disasters 28:16-40

Smyth I (2009) Gender in climate change and disaster risk reduction, Manila, October 2008. Dev Pract 19:799-802

Turner II. BL, Kasperson RE, Matson P, McCarthy JJ, Corell RW, Christensen L, Eckley N, Kasperson JX, Luers A, Martello ML, Polsky C, Pulsipher A, Schiller A (2003) Framework for vulnerability analysis in sustainability science. In: Proceedings of the National Academy of Sciences of the United States of America, vol 100, pp 8074-8079 
Twigg J (1999) The age of accountability? Future community involvement in disaster reduction. Aust J Emerg Manag 14:51-58

UNDP (2010) Gender and disasters. The United Nations Development Programme

UNISDR (2009) Making disaster risk reduction gender sensitive: policy and practical guidelines. United Nations Office for Disaster Risk Reduction

UNISDR (2015) The Sendai Framework for Disaster Risk Reduction 2015-2030. United Nations Office for Disaster Risk Reduction

UN Women (2016) Time to act on gender, climate change and disaster risk reduction. The United Nations Entity for Gender Equality and the Empowerment of Women

Werner EE, Smith RS (1982) Vulnerable but invincible: a study of resilient children and youth. McGrawHill, New York

Wisner B, Blaikie PM, Cannon T, Davis I (2004) At risk: natural hazards, people's vulnerability, and disasters. Taylor \& Francis Ltd, London

Wisner B, Berger G, Gaillard JC (2016) We've seen the future, and it's very diverse: beyond gender and disaster in West Hollywood, California. Gend Place Cult 24:27-36

Wright JD, Rossi PH, Wright SR, Weber-Burdin E (1979) After the clean-up: long-range effects of natural disasters. SAGE, Beverly Hills

Yin RK (2003) Case study research: design and methods. Sage Publications, Thousand Oaks 